\title{
Ultrasmall, Ligand-Free Ag Nanoparticles with High Antibacterial Activity Prepared by Pulsed Laser Ablation in Liquid
}

\author{
László Körösi, ${ }^{1}$ Marina Rodio, ${ }^{2}$ Dora Dömötör, ${ }^{3}$ Tamás Kovács, ${ }^{3}$ \\ Szilvia Papp, ${ }^{3}$ Alberto Diaspro, ${ }^{2}$ Romuald Intartaglia, ${ }^{2}$ and Szabolcs Beke ${ }^{2}$ \\ ${ }^{1}$ Research Institute for Viticulture and Oenology, University of Pécs, Pázmány Péter Utca 4, Pécs 7634, Hungary \\ ${ }^{2}$ Department of Nanophysics, Istituto Italiano di Tecnologia (IIT), Via Morego 30, 16163 Genova, Italy \\ ${ }^{3}$ Department of Biotechnology, Nanophage Therapy Center, Enviroinvest Corporation, Kertváros Utca 2, Pécs 7632, Hungary
}

Correspondence should be addressed to László Kőrösi; ltkorosi@gmail.com and Szabolcs Beke; szabolcs.beke@iit.it

Received 27 January 2016; Revised 9 April 2016; Accepted 11 April 2016

Academic Editor: Chellappan R. Raj

Copyright (C) 2016 László Körösi et al. This is an open access article distributed under the Creative Commons Attribution License, which permits unrestricted use, distribution, and reproduction in any medium, provided the original work is properly cited.

\begin{abstract}
Since ancient times, silver and its compounds have been known to have a broad spectrum of antimicrobial activities for bacteria, fungi, and viruses. Due to the increasing bacterial resistance to classic antibiotics, the investigations of Ag NPs have increased. Herein, we present the preparation of ligand-free Ag NPs with 3 and $20 \mathrm{~nm}$ sizes by applying picosecond laser ablation in liquid at 355 and $1065 \mathrm{~nm}$. Our laser processing system allows a high control on particle sizes. The produced nanoparticles were characterized by means of transmission electron microscopy, UV-Vis spectroscopy, and X-ray diffraction. The size effect on the antibacterial activity of Ag NPs was tested against E. coli and S. aureus. The growth curves of bacteria were monitored at $0-5 \mathrm{mg} / \mathrm{L}$ of Ag NPs by a multimode microplate reader. The size effects as well as the concentration of Ag NPs on their antibacterial activity are discussed.
\end{abstract}

\section{Introduction}

By virtue of its excellent antimicrobial activity, silver is one of the most extensively studied metals in the past decade. The treatment of bacterial infections is not easy when bacteria become resistant against antibiotics. Silver nanoparticles (Ag NPs) with broad spectrum of antibacterial activity have already been successfully used against multiresistant strains as well [1-3]. In most studies, the effect of the concentration of Ag NPs has been investigated [4]; however, the antibacterial activity of Ag NPs also depends on the particle size and on the surface-adsorbed molecules. These relevant papers can be found in lower number [5-11].

Ag NPs prepared by different synthesis methods can show different surface behavior and toxicity. Moreover, the tuning of the nanoparticles' size is often difficult when using only one sort of synthesis method. The comparison of the results of the size effect is also complicated when particles are coated with capping agents.

The citrate reduction is the most frequently applied chemical synthesis method, resulting in Ag NPs with diameter in the range between 10 and $100 \mathrm{~nm}$ [8]. Smaller Ag NPs can be produced at higher $\mathrm{pH}$ or by using stronger reducing agents such as sodium borohydride [9-11]. Removing the reducing agent residues is usually performed by a washing procedure. This includes a centrifugation step which results in hardly redispersible particle agglomerates. Ag NPs with $5 \mathrm{~nm}$ in diameter were prepared by the borohydride reduction method and the particles were stabilized with PVP [10] and citrate [11]. These were the smallest Ag NPs in the literature, which were studied to reveal their antibacterial activity. The influence of the applied chemicals (e.g., reducing and capping agents, surfactants) in the syntheses can also change the antibacterial efficacy of Ag NPs. However, these 
preparation routes have drawbacks from synthetic standpoint attributed to the use of hazardous surfactants which are not suitable for biomedical applications.

Pulsed laser ablation in liquid (PLAL) has emerged as an alternative approach for the generation of wide range of nanomaterials (semiconductors, metals) with high purity (i.e., without chemicals on the surface of the nanoparticles) [12-17]. PLAL has several advantages, such as (i) a chemically clean synthesis, without the requirement of chemical precursors, (ii) simplicity, since it is performed at ambient conditions, without the need of extreme temperature and pressure conditions, and (iii) versatility, since the obtained NPs are in colloidal solution form, giving the opportunity for further nanoscale manipulations, such as functionalization [15] and a high production yield [16]. The surface of the particles prepared by laser ablation in liquid is therefore pure and does not contain reducing agents residues or other moleculesrelated steric stabilization. This is an essential aspect since the presence of surface modifiers can strongly influence the antibacterial activity of Ag NPs. This fact suggests that particles prepared by laser ablation are the most suitable for antibacterial investigations. Recently, Pandey et al. [18] synthesized Ag NPs with 9-27 nm by pulsed laser ablation. Those Ag NPs were polydisperse exhibiting relatively wide particle-size distribution. With our laser processing system a higher control of particle distribution can be achieved.

In this study, we prepared ligand-free Ag NPs with 3 and $20 \mathrm{~nm}$ mean sizes using pulsed laser ablation of silver immersed in deionized water. Our Ag NPs possess excellent size controlling which allowed comparing the size effect on antibacterial activity of Ag NPs. The particles were characterized in detail by means of UV-Vis spectroscopy, transmission electron microscopy, and $\mathrm{X}$-ray diffraction. The antibacterial activity was tested against Escherichia coli and vancomycinintermediate resistant Staphylococcus aureus bacteria.

\section{Materials and Methods}

2.1. Synthesis of Ligand-Free Ag Nanoparticles. Pulsed laser ablation of silver target in liquid was performed by applying the fundamental beam at $1064 \mathrm{~nm}$ and its third-harmonic beam at $355 \mathrm{~nm}$, of a mode-locked amplified Nd:YAG laser (Leopard, Continuum) providing pulses of 60 ps time duration, at a repetition rate of $20 \mathrm{~Hz}$. The laser beam has a flattop profile due to a serrated aperture relay imaging system between the oscillator and the amplifier. The silver target (99.999\% from Sigma Aldrich) was placed in a glass cell containing $4 \mathrm{~mL}$ of deionized water. The laser beam with a diameter of $6 \mathrm{~mm}$ was focused $10 \mathrm{~mm}$ below the target surface using a lens with a focus of $30 \mathrm{~cm}$. The laser power was adjusted to $10 \mathrm{~mJ} /$ pulse and the ablation was carried out for $90 \mathrm{~min}$. The formation of NPs was estimated by the change of the water color during the ablation process. Prior to each experiment the target was mechanically polished and then washed with the same liquid used for the ablation several times to remove impurity from the surface. During the ablation, the target was rotated to achieve a uniform irradiation on the silver surface. All characterization measurements were performed 1 day after the preparation of the colloidal solution.

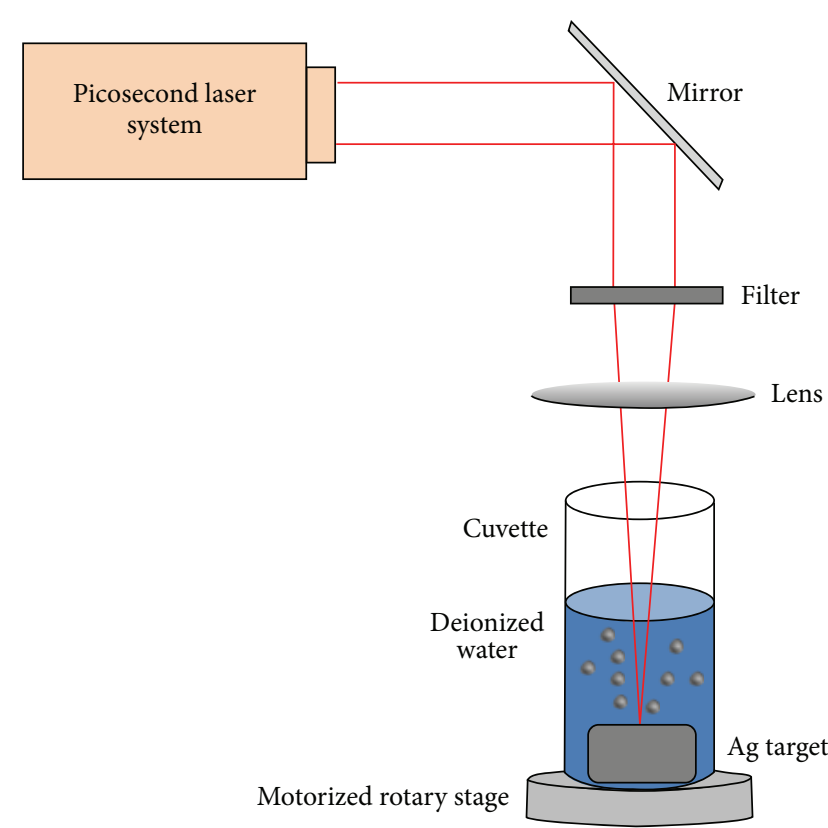

FIGURE 1: Schematic illustration of Ag NPs colloidal solution prepared by ultrafast pulsed laser ablation of Ag target in deionized water.

2.2. Chemical Analysis. The quantity of silver in the obtained colloidal solutions was evaluated by Inductively Coupled Plasma Optical Emission Spectrometry (ICAP 6300, Duo Thermo Scientific). $100 \mu \mathrm{L}$ solution of NPs colloidal solution was introduced in aqua regia, and after an overnight acid digestion the final volume was adjusted with Milli-Q water to $25 \mathrm{~mL}$. The dilution factor was taken into consideration while determining the final concentration.

2.3. Electron Microscopy. Transmission electron microscopy (TEM) images were acquired by a JEOL Jem 1011 microscope working at an acceleration voltage of $100 \mathrm{keV}$. TEM/STEM samples were prepared by dropping the colloidal solutions directly onto carbon-coated 300-mesh copper grids and the solution was allowed to evaporate.

2.4. Optical Analysis. Optical absorption spectra were recorded in a quartz cuvette (10 mm, Helma), using a Cary 6000 UV-Vis double beam spectrophotometer. The scan range was $200-800 \mathrm{~nm}$ with a $600 \mathrm{~nm} \mathrm{~min}^{-1}$ rate.

2.5. XRD Structural Analysis. XRD patterns were recorded on a Smartlab $9 \mathrm{~kW}$ Rigaku diffractometer, equipped with a copper-rotating anode. The X-ray source was operated at $40 \mathrm{kV}$ and $150 \mathrm{~mA}$. A Gobel mirror was used to obtain a parallel beam and to suppress $\mathrm{Cu} \mathrm{K}_{\beta}$ radiation (1.392 $\AA$ ). The measurements were performed using a $2 \theta$ scan.

2.6. Determination of Bacterial Growth. Ag NPs were tested against Gram-negative (Escherichia coli, ATCC25922) and Gram-positive bacteria (vancomycin-intermediate resistant Staphylococcus aureus, ATCC700699). Bacteria were grown 

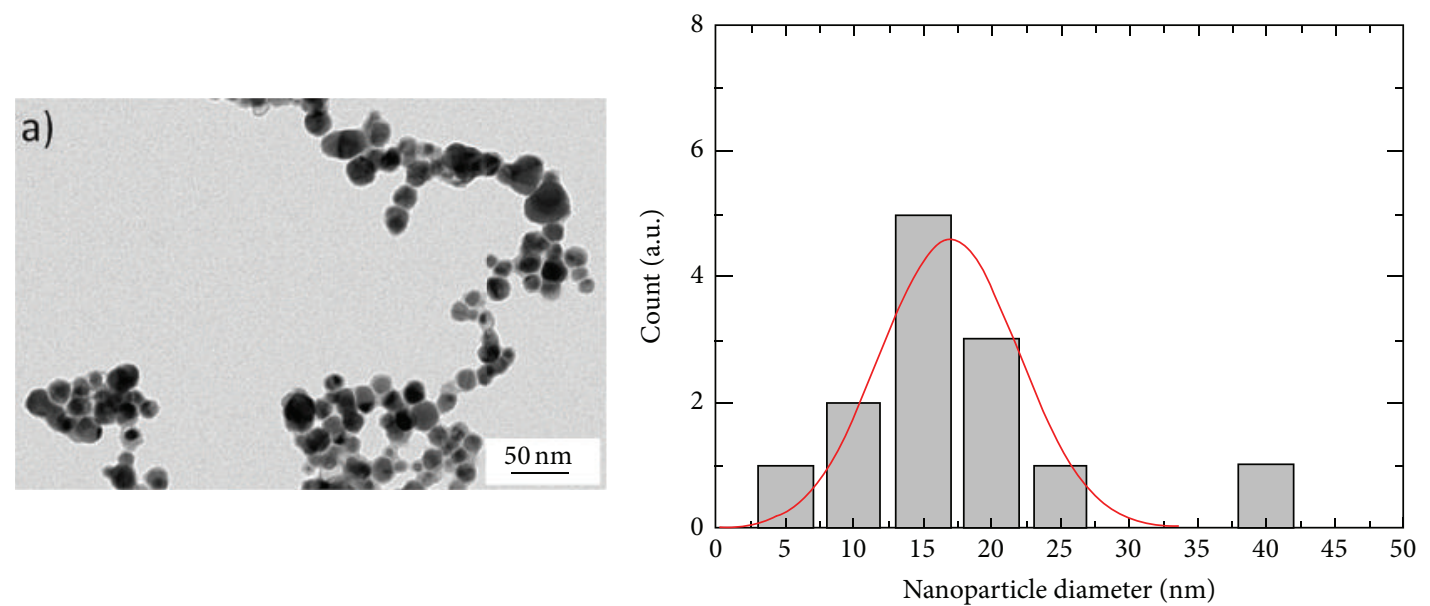
Nanoparticle

(a)
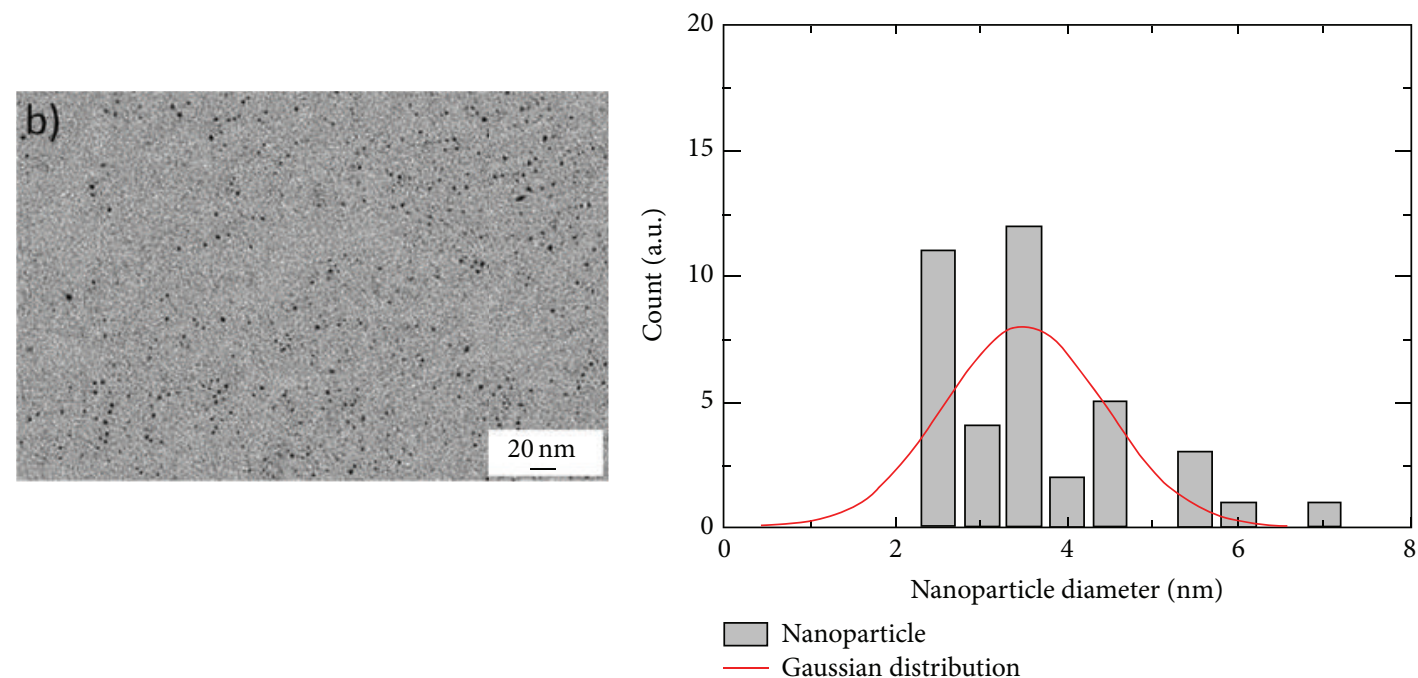

(b)

FIGURE 2: TEM analyses of the ligand-free Ag colloidal solution prepared by picosecond laser ablation of silver target in deionized water using different laser wavelengths: (a) $1064 \mathrm{~nm}$ and (b) $355 \mathrm{~nm}$. On the right side the corresponding size histogram is presented.

in LB medium (Luria broth). $10.0 \mathrm{~g}$ of pancreatic digest of casein and $5.0 \mathrm{~g}$ of $\mathrm{NaCl}$ and $5.0 \mathrm{~g}$ yeast extract were dissolved in $1.0 \mathrm{~L}$ of deionized water. The $\mathrm{pH}$ was adjusted to 7.0 , and finally, the obtained solution was treated in an autoclave for $25 \mathrm{~min}$ at $121^{\circ} \mathrm{C}$ [19]. $1500 \mu \mathrm{L}$ of the suspensions of bacteria in LB medium (approximately $10^{6} \mathrm{CFU} / \mathrm{mL}$ ) was transferred into $2 \mathrm{~mL}$ Eppendorf tubes, and then $200 \mu \mathrm{L}$ of aqueous dispersion of Ag NPs in different concentration and size was added. LB medium without bacteria was used as a negative control. Inoculated LB medium without Ag NPs served as a positive control. From these bacteria suspensions, $150 \mu \mathrm{L}$ portions were transferred into the sterile wells of a covered microplate with flat bottom (Sarstedt Inc.). The measurements were performed in six replicates. Bacterial growth was monitored in the Synergy HT multimode microplate reader (BioTek, Winooski, VT) and incubated at $37^{\circ} \mathrm{C}$ for $24 \mathrm{~h}$, with shaking at $1080 \mathrm{rpm}$ ("medium" scale of the multimode reader). The reader automatically measured the absorbance at $600 \mathrm{~nm}$ of culture samples at $15 \mathrm{~min}$ intervals.

\section{Results and Discussion}

3.1. Laser Synthesis of Ligand-Free Ag Nanoparticles. Ag NPs colloidal solution was prepared by picosecond pulsed laser ablation of $\mathrm{Ag}$ target immersed in deionized water, as illustrated in Figure 1. Figure 2 shows typical TEM images (left side) with the corresponding size histogram (right side) of Ag NPs colloidal solution obtained by two different wavelength irradiations. Ag NPs have pseudospherical morphology and smooth surface. The mean diameter was found to be around $18 \mathrm{~nm}$ (Figure 2(a)) and $3.5 \mathrm{~nm}$ (Figure 2(b)) when using 


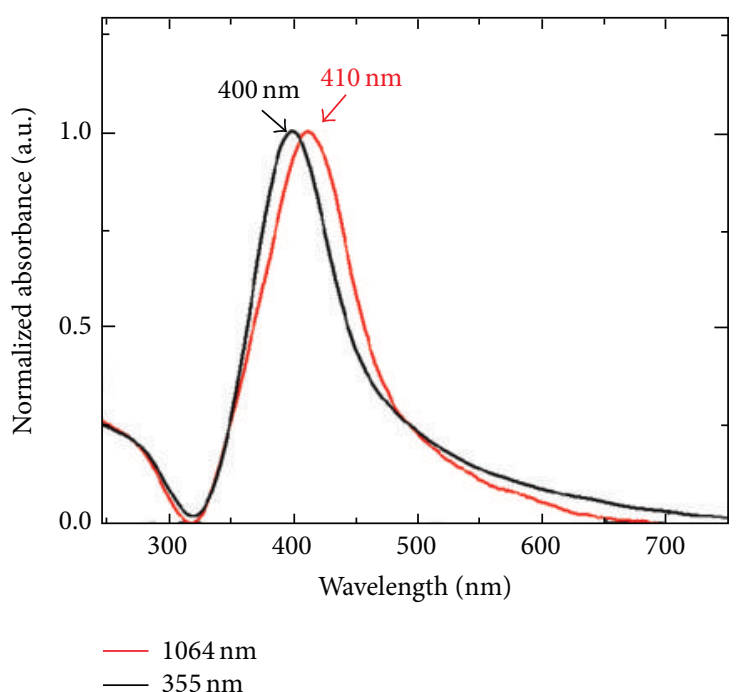

(a)

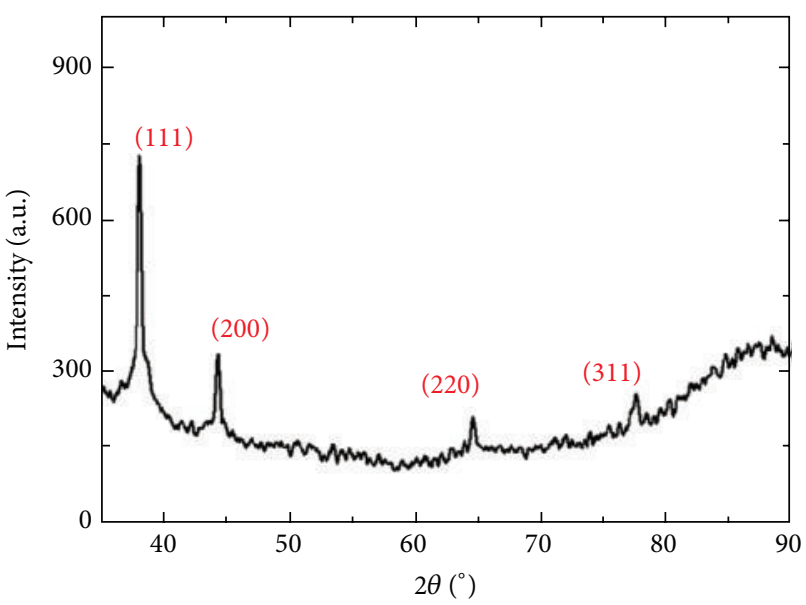

(b)

FIGURE 3: (a) UV-Vis absorption spectra of the ligand-free Ag colloidal solution produced via picosecond laser ablation of a silver target in deionized water using different laser wavelength, sample A: $1064 \mathrm{~nm}$ and sample B: $355 \mathrm{~nm}$. (b) XRD pattern of the ligand-free Ag NPs $(d=20 \mathrm{~nm})$ produced via picosecond laser ablation of a silver target in deionized water. Ag NPs exhibit the (111), (200), (220), and (311) main peaks of cubic Ag phases.

$1064 \mathrm{~nm}$ and $355 \mathrm{~nm}$ laser wavelength irradiations, respectively. In addition to electron microscopy, UV-Vis spectroscopy analysis was also performed. In Figure 3(a), the normalized absorption spectra of resulting colloidal solution are reported and prepared by PLAL at two different wavelengths. The plasmon peak position is shifted from $400 \mathrm{~nm}$ to $410 \mathrm{~nm}$ with the increase of wavelength irradiation from $355 \mathrm{~nm}$ to $1064 \mathrm{~nm}$. This phenomenon indicates the formation of ultrasmall Ag NPs of around $3 \mathrm{~nm}$ and larger one with a mean size of $20 \mathrm{~nm}$, respectively. This wavelength-dependent behavior is in accordance with previous Ag nanoparticles formation by laser ablation [17]. XRD investigations of Ag NPs exhibited the crystalline structure displaying diffraction peaks compatible with Ag single phases with lattice parameters $\left(a_{\mathrm{Ag}}=4.086 \AA ; a_{\mathrm{Au}}=4.078 \AA\right.$ ) and space groups (cubic Fm-3 m) (Figure 3(b)). For further antibacterial studies, we evaluated the NPs colloidal solution concentration estimating the concentration of Ag in solution after ablation via ICP-OES measurements.

3.2. Ag Nanoparticle Size Effect on the Bacterial Growth. The bacterial growth curves at different Ag NPs concentrations $(0-5 \mathrm{mg} / \mathrm{L})$ are presented in Figure 4. Figure 4(a) shows that Ag NPs with $3 \mathrm{~nm}$ of mean diameter strongly influenced the growth of $E$. coli in LB medium. The presented curves can be divided at least into four distinct phases: lag phase, log phase, stationary phase, and death phase. It can be clearly seen that the lag phase was considerably extended (from 1 to $11 \mathrm{~h}$ ) when the concentration of Ag increased from 0 to $3 \mathrm{mg} / \mathrm{L}$. By further increasing the concentration to $5 \mathrm{mg} / \mathrm{L}$ the absorbance did not change within $18 \mathrm{~h}$, demonstrating that the bacteria were not able to multiply, and therefore there was no increase in the cell mass. This confirmed that E. coli bacteria were killed by the Ag NPs treatment with $5 \mathrm{mg} / \mathrm{L}$. The treatment at $<3 \mathrm{mg} / \mathrm{L}$ caused only partial death of the population, and therefore the absorbance could increase considerably after a longer lag period. It should be noted that the growth rate at $3 \mathrm{mg} / \mathrm{L}$ was lower as indicated by a smaller slope of the log phase. Moreover, the absorbance could not reach the value observed for the samples with lower Ag NPs concentration. In this case, the hindering of Ag on the proliferation is more evident. The E. coli growth curves recorded in the presence of $20 \mathrm{~nm} \mathrm{Ag} \mathrm{NPs} \mathrm{(Figure} \mathrm{4(b))} \mathrm{revealed} \mathrm{that} \mathrm{the} \mathrm{hindering}$ of Ag NPs with bigger particle size on the proliferation was lower. There was no significant difference in the length of the lag phase when the Ag concentration was increased to $5 \mathrm{mg} / \mathrm{L}$. However, the absorbance maxima decreased with increasing Ag concentration, indicating lower cell density in the suspensions.

The antibacterial effect of Ag NPs of $3 \mathrm{~nm}$ was also observed for S. aureus (Figure 4(c)). Similarly for the experiments with $E$. coli, the lag phase was also extended when higher Ag concentrations were applied. From the comparison of the results on two bacteria, shorter lag phase was observed for S. aureus, suggesting that the hindering effect of Ag was lower for $S$. aureus than for E. coli. This is probably due to the difference in their wall thickness/structure. E. coli is a Gramnegative bacterium with thinner wall and therefore Ag NPs can easily penetrate into the cell and then their antibacterial effect (namely, release of $\mathrm{Ag}^{+}$ions and reactive oxygen generation) could be realized. Pandey et al. [18] also found that growth of the Gram-negative bacteria is more sensitive for Ag NPs. On the growth curves of S. aureus, the absorbance maxima did not depend on the Ag concentration. Moreover, the death phase could not be observed within the course 


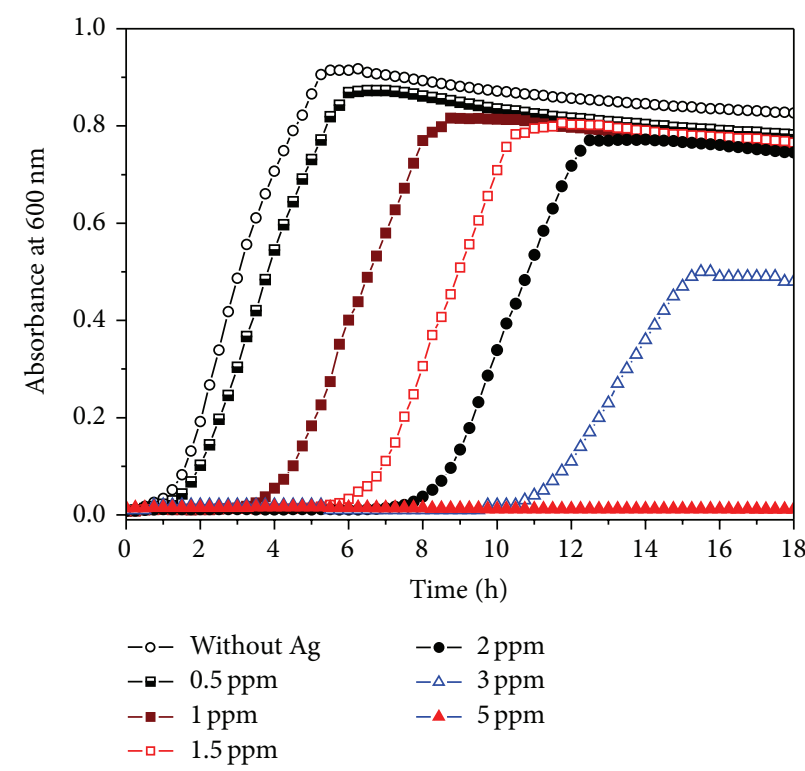

(a)

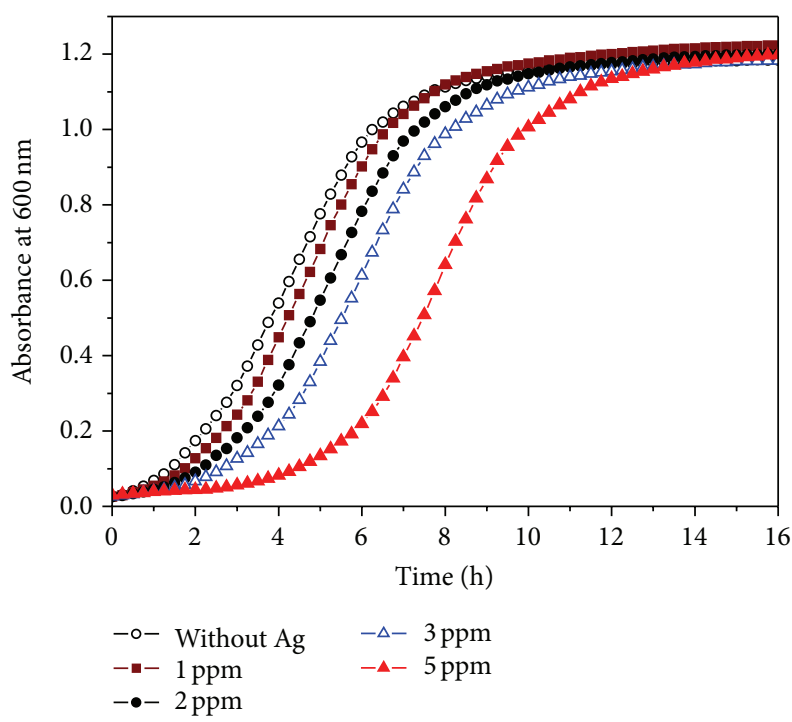

(c)

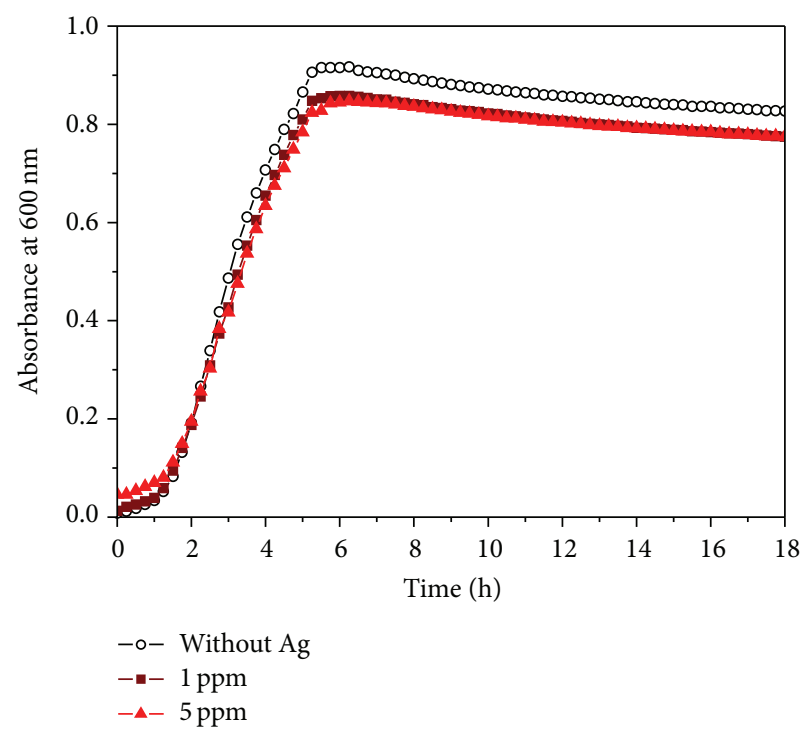

(b)

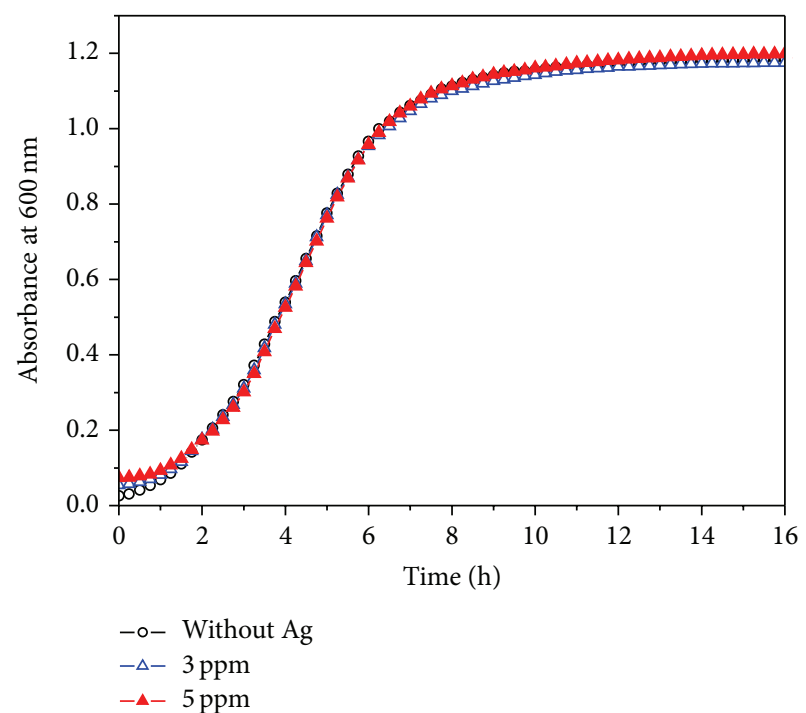

(d)

Figure 4: Growth curves of E. coli (ATCC 25922) at different Ag NPs concentrations. The mean diameter of Ag NPs is (a) $3 \mathrm{~nm}$ and (b) $20 \mathrm{~nm}$. Growth curves of vancomycin-intermediate resistant $S$. aureus (ATCC 700699) in the absence and presence of Ag NPs are shown in panel (c) and (d) where the mean diameter of Ag NPs is $3 \mathrm{~nm}$ and $20 \mathrm{~nm}$, respectively.

of the experiments. Figure $4(\mathrm{~d})$ shows that the growth of S. aureus was not influenced by $20 \mathrm{~nm} \mathrm{Ag} \mathrm{NPs} \mathrm{(up} \mathrm{to} 5 \mathrm{mg} / \mathrm{L}$ ). All of these observations demonstrate that Ag NPs have lower antibacterial effect against vancomycin-intermediate resistant $S$. aureus.

The higher antibacterial activity of $3 \mathrm{~nm}$ Ag NPs was confirmed independently in other liquid phase experiments in which Ag NPs were added to the bacteria suspensions and they were mixed with vortex and then incubated at $37^{\circ} \mathrm{C}$ for $60 \mathrm{~min}$. The final concentration of Ag was $5 \mathrm{mg} / \mathrm{L}$. Finally, the aliquots of the mixtures were properly diluted and plated on LB agar and then the colonies were counted after incubation for $12 \mathrm{~h}$. Figure 5 clearly shows that viable bacterium cell was not detected after the treatment of E. coli with $3 \mathrm{~nm}$ Ag NPs. In case of $20 \mathrm{~nm}$, only a partial death of bacteria was observed. The cell numbers were $4.2 \times 10^{5}$ and $8.2 \times 10^{5} \mathrm{CFU} / \mathrm{mL}$ for the $20 \mathrm{~nm} \mathrm{Ag} \mathrm{NPs} \mathrm{and} \mathrm{for} \mathrm{the} \mathrm{control} \mathrm{E.} \mathrm{coli} \mathrm{suspensions,}$ respectively. In case of $S$. aureus, $3 \mathrm{~nm} \mathrm{Ag} \mathrm{NPs} \mathrm{possessed}$ lower efficiency (Figure 5). The living cells in the suspensions were $2.6 \times 10^{3}, 4.4 \times 10^{5}$, and $9.6 \times 10^{5}$ for 3 and $20 \mathrm{~nm} \mathrm{Ag} \mathrm{NPs}$ and the control sample without $\mathrm{Ag}$, respectively.

The antibacterial effect of Ag NPs for E. coli was also demonstrated by the drop-on-lawn technique (Figure 6). $20 \mu \mathrm{L}$ of 5 or $50 \mathrm{mg} / \mathrm{L} \mathrm{Ag} \mathrm{NPs} \mathrm{dispersion} \mathrm{was} \mathrm{dropped} \mathrm{onto}$ 

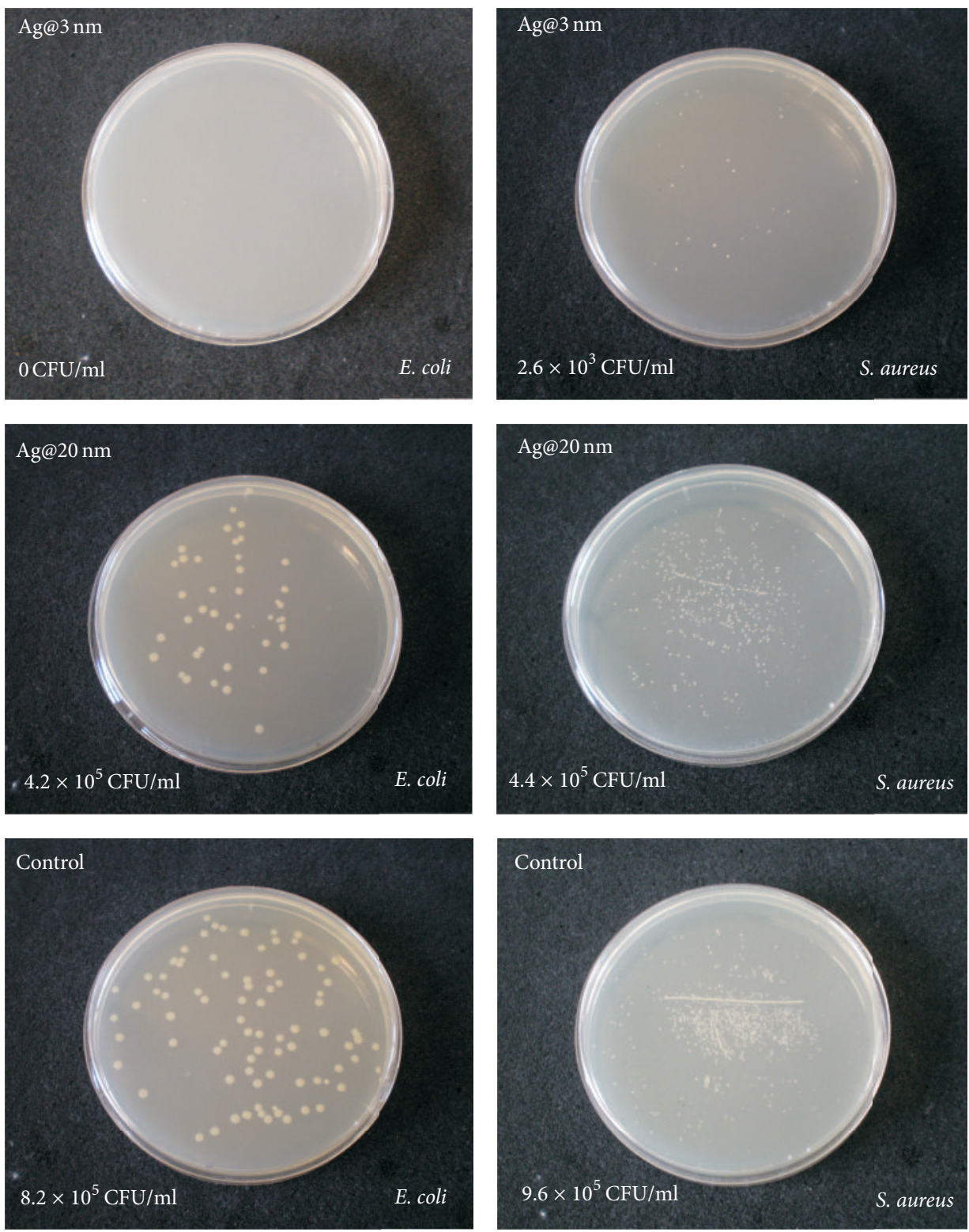

FIGURE 5: Antibacterial activity of Ag NPs with different sizes against E. coli (ATCC 25922) and vancomycin-intermediate resistant S. aureus ATCC 700699.

a lawn of E. coli grown on LB agar. A sharp inhibition zone was observed for $50 \mathrm{mg} / \mathrm{L}$ of $3 \mathrm{~nm} \mathrm{Ag} \mathrm{NPs} \mathrm{while} 5 \mathrm{mg} / \mathrm{L}$ resulted in only a turbid zone (marked with arrows in Figure 6). For Ag NPs with $20 \mathrm{~nm}$, the edge of inhibition zone could not be distinguished, confirming lower antibacterial effect of the larger particles.

The effectiveness of the treatment was different in liquid phase and solid phase (on bacterium lawn) experiments. While $5 \mathrm{mg} / \mathrm{L} \mathrm{Ag}$ dispersion killed all bacteria in liquid, higher concentration was needed for bacterium colonies on agar. This is probably due to the different conditions and the different Ag: cell ratio. The appropriate Ag: cell ratio is an important factor since insufficient amount of $\mathrm{Ag}$ resulted in only a partial death of bacterium population and then the proliferation can continue.

\section{Conclusions}

Ultrasmall Ag NPs with narrow-size distribution were successfully prepared in aqueous medium by laser ablation. This method allows Ag NPs fabrication without any additives for the NPs stabilization. These ligand-free Ag NPs were tested against $E$. coli and vancomycin-intermediate resistant $S$. aureus. We found that particle size of Ag NPs strongly influenced their antibacterial properties. While the antibacterial activity of Ag NPs with $3 \mathrm{~nm}$ was very high, especially against E. coli, NPs with $20 \mathrm{~nm}$ exhibited low antibacterial effect even though their concentration reached $5 \mathrm{mg} / \mathrm{L}$. However, the Gram-positive $S$. aureus can partially withstand $3 \mathrm{~nm} \mathrm{Ag} \mathrm{NPs} \mathrm{up} \mathrm{to} 5 \mathrm{mg} / \mathrm{L}$. Our results indicate that laser ablation in liquid is a promising tool to produce 

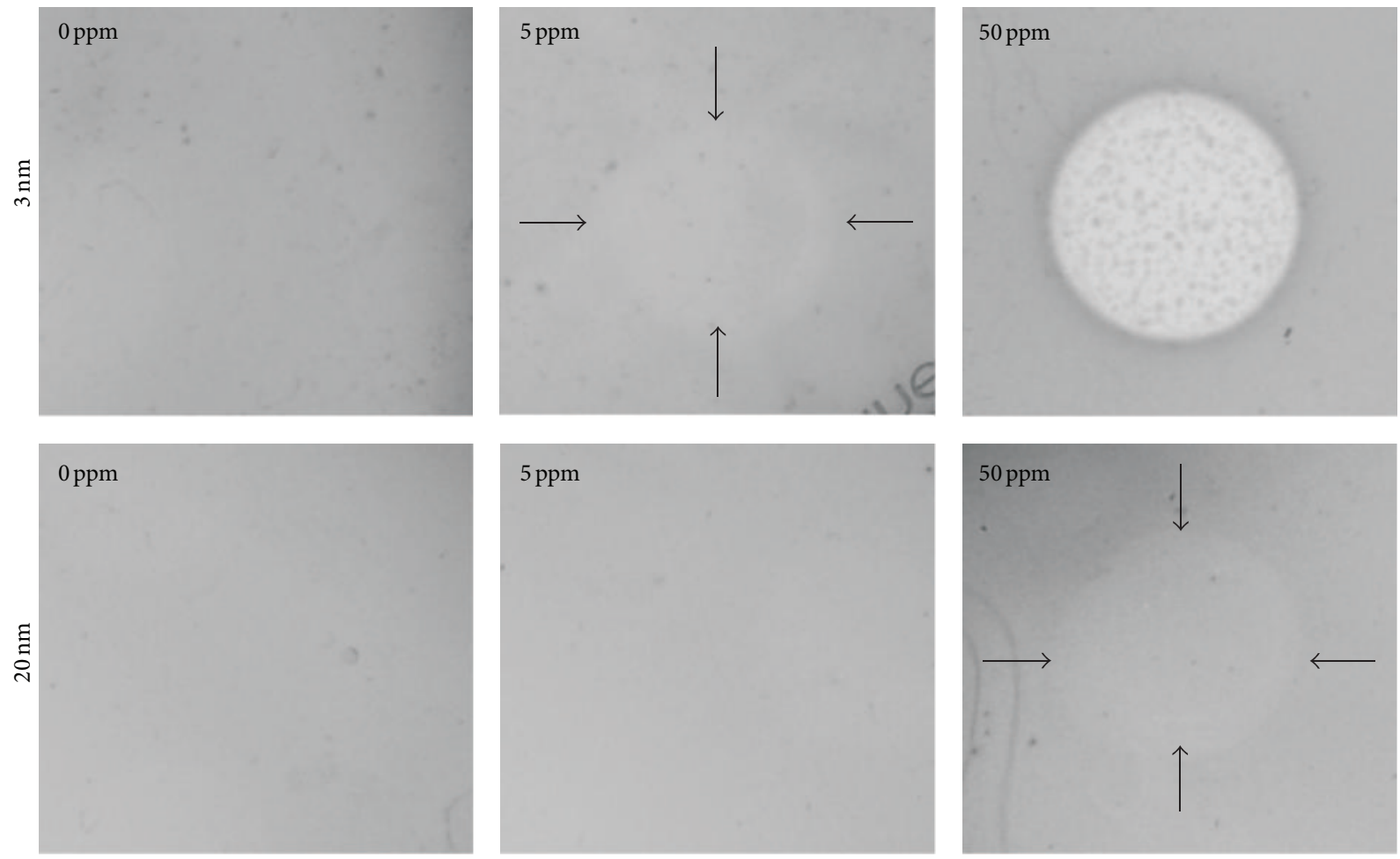

Figure 6: Antibacterial effect of Ag NPs with different sizes and concentrations against E. coli (ATCC 25922) lawn on LB agar. Turbid zones are marked with arrows.

well-size-controlled ligand-free Ag NPs with high antibacterial activity.

\section{Competing Interests}

The authors declare that they have no competing interests.

\section{References}

[1] M. K. Rai, S. D. Deshmukh, A. P. Ingle, and A. K. Gade, "Silver nanoparticles: the powerful nanoweapon against multidrugresistant bacteria," Journal of Applied Microbiology, vol. 112, no. 5, pp. 841-852, 2012.

[2] G. Franci, A. Falanga, S. Galdiero et al., "Silver nanoparticles as potential antibacterial agents," Molecules, vol. 20, no. 5, pp. 8856-8874, 2015.

[3] H. H. Lara, N. V. Ayala-Núñez, L. D. C. I. Turrent, and C. R. Padilla, "Bactericidal effect of silver nanoparticles against multidrug-resistant bacteria," World Journal of Microbiology and Biotechnology, vol. 26, no. 4, pp. 615-621, 2010.

[4] Y. Zhou, Y. Kong, S. Kundu, J. D. Cirillo, and H. Liang, "Antibacterial activities of gold and silver nanoparticles against Escherichia coli and bacillus Calmette-Guérin," Journal of Nanobiotechnology, vol. 10, article 19, 2012.

[5] A. Ivask, I. Kurvet, K. Kasemets et al., "Size-dependent toxicity of silver nanoparticles to bacteria, yeast, algae, crustaceans and mammalian cells in vitro," PLoS ONE, vol. 9, no. 7, Article ID e102108, 2014.

[6] E. Caballero-Díaz, C. Pfeiffer, L. Kastl et al., "The toxicity of silver nanoparticles depends on their uptake by cells and thus on their surface chemistry," Particle and Particle Systems Characterization, vol. 30, no. 12, pp. 1079-1085, 2013.

[7] A. R. Gliga, S. Skoglund, I. O. Wallinder, B. Fadeel, and H. L. Karlsson, "Size-dependent cytotoxicity of silver nanoparticles in human lung cells: the role of cellular uptake, agglomeration and Ag release," Particle and Fibre Toxicology, vol. 11, no. 1, article 11, 2014.

[8] Y. Jeong, D. W. Lim, and J. Choi, "Assessment of size-dependent antimicrobial and cytotoxic properties of silver nanoparticles," Advances in Materials Science and Engineering, vol. 2014, Article ID 763807, 6 pages, 2014.

[9] G. A. Martinez-Castanon, N. Niño-Martínez, F. MartínezGutierrez, J. R. Martínez-Mendoza, and F. Ruiz, "Synthesis and antibacterial activity of silver nanoparticles with different sizes," Journal of Nanoparticle Research, vol. 10, no. 8, pp. 1343-1348, 2008.

[10] Z. Lu, K. Rong, J. Li, H. Yang, and R. Chen, "Size-dependent antibacterial activities of silver nanoparticles against oral anaerobic pathogenic bacteria," Journal of Materials Science: Materials in Medicine, vol. 24, no. 6, pp. 1465-1471, 2013.

[11] S. Agnihotri, S. Mukherji, and S. Mukherji, "Size-controlled silver nanoparticles synthesized over the range $5-100 \mathrm{~nm}$ using the same protocol and their antibacterial efficacy," RSC Advances, vol. 4, no. 8, pp. 3974-3983, 2014.

[12] R. Intartaglia, G. Das, K. Bagga et al., "Laser synthesis of ligandfree bimetallic nanoparticles for plasmonic applications," Physical Chemistry Chemical Physics, vol. 15, no. 9, pp. 3075-3082, 2013.

[13] R. Intartaglia, K. Bagga, A. Genovese et al., "Influence of organic solvent on optical and structural properties of ultrasmall silicon dots synthesized by UV laser ablation in liquid," 
Physical Chemistry Chemical Physics, vol. 14, no. 44, pp. 1540615411, 2012.

[14] R. García-Calzada, M. Rodio, K. Bagga et al., "Facile laserassisted synthesis of inorganic nanoparticles covered by a carbon shell with tunable luminescence," RSC Advances, vol. 5, no. 62, pp. 50604-50610, 2015.

[15] K. Bagga, A. Barchanski, R. Intartaglia et al., "Laser-assisted synthesis of Staphylococcus aureus protein-capped silicon quantum dots as bio-functional nanoprobes," Laser Physics Letters, vol. 10, no. 6, Article ID 065603, 2013.

[16] R. Intartaglia, K. Bagga, and F. Brandi, "Study on the productivity of silicon nanoparticles by picosecond laser ablation in water: towards gram per hour yield," Optics Express, vol. 22, no. 3, pp. 3117-3127, 2014.

[17] T. Tsuji, K. Iryob, N. Watanabeb, and M. Tsujia, "Preparation of silver nanoparticles by laser ablation in solution: influence of laser wavelength on particle size," Applied Surface Science, vol. 202, no. 1-2, pp. 80-85, 2002.

[18] J. K. Pandey, R. K. Swarnkar, K. K. Soumya et al., "Silver nanoparticles synthesized by pulsed laser ablation: as a potent antibacterial agent for human enteropathogenic gram-positive and gram-negative bacterial strains," Applied Biochemistry and Biotechnology, vol. 174, no. 3, pp. 1021-1031, 2014.

[19] R. M. Atlas, Handbook of Microbiological Media, CRC Press, Boca Raton, Fla, USA, ASM Press, Washington, DC, USA, 4th edition, 2010. 

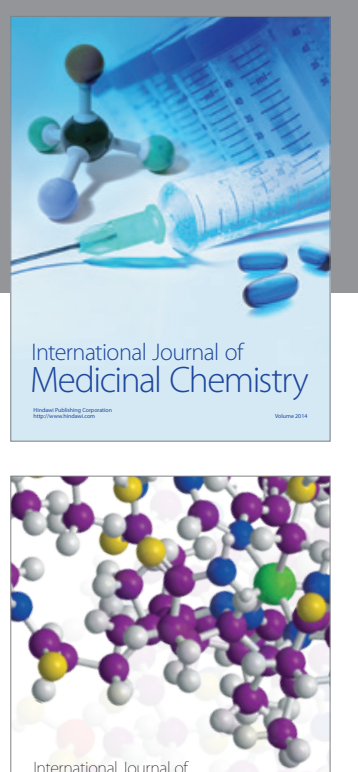

Carbohydrate Chemistry

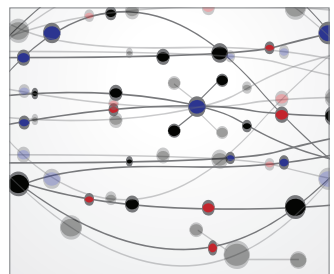

The Scientific World Journal
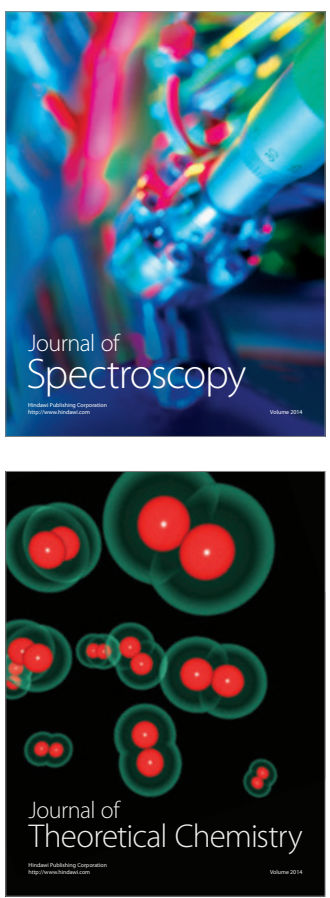
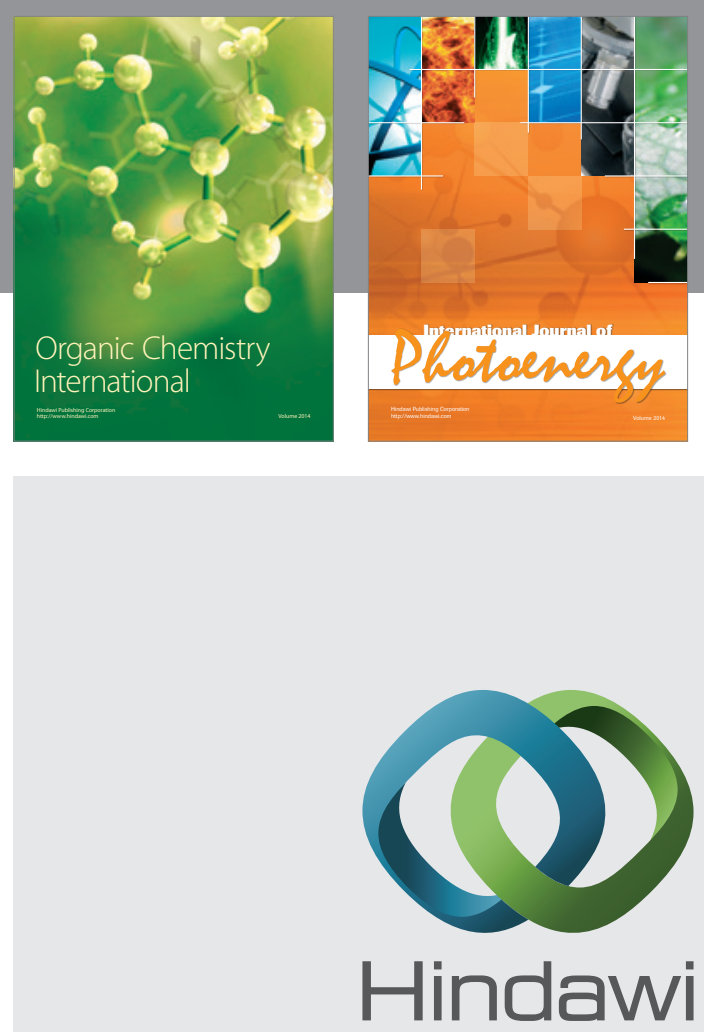

Submit your manuscripts at

http://www.hindawi.com

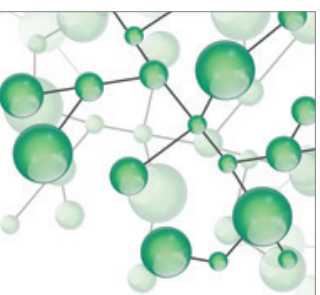

International Journal of

Inorganic Chemistry

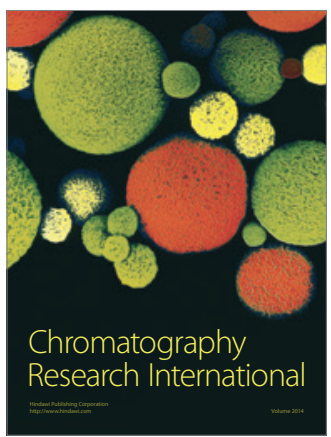

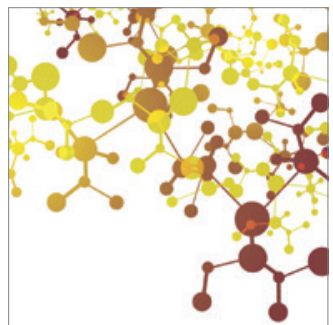

Applied Chemistry
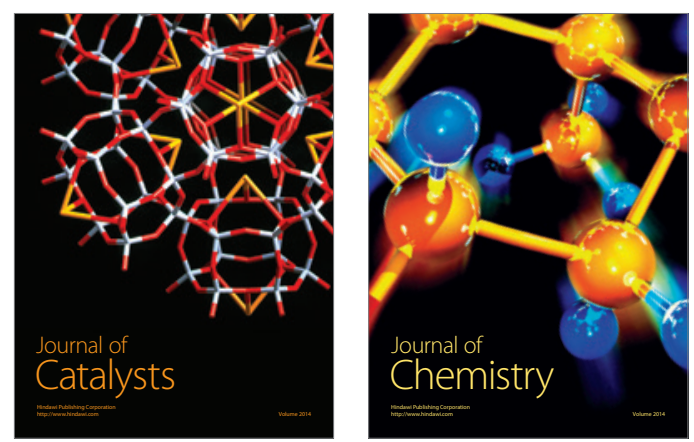
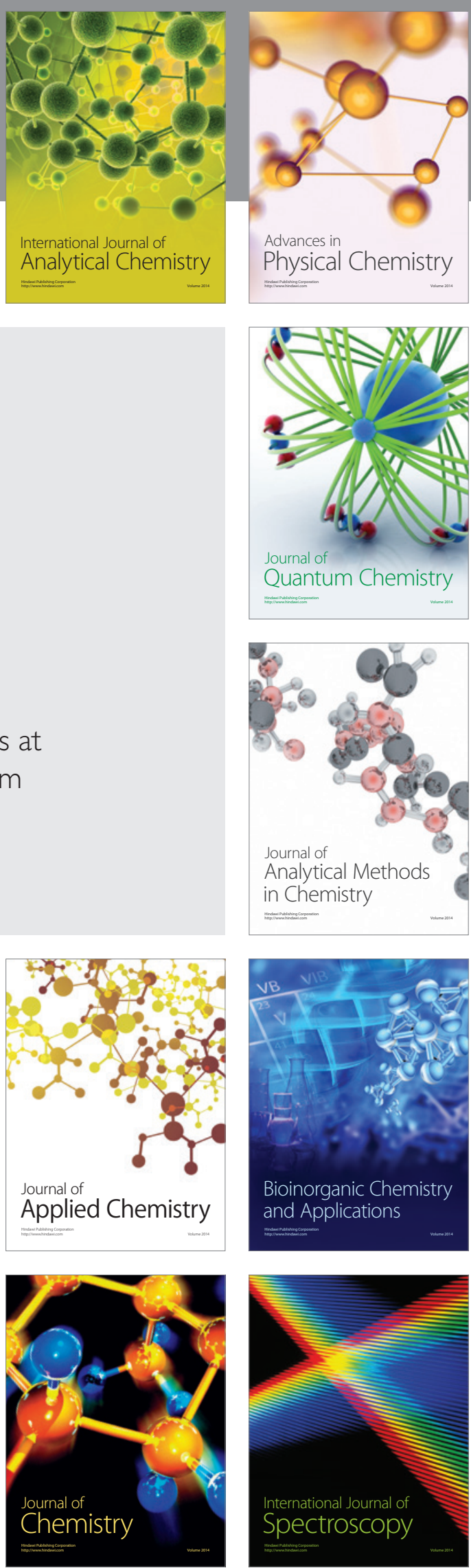